\title{
AS TEMÁTICAS UTILIZADAS PELOS ACADÊMICOS NOS TRABALHOS FINAIS DO CURSO DE PUBLICIDADE E PROPAGANDA DA UNIVERSIDADE FRANCISCANA ${ }^{1}$
}

\author{
THE THEMES USED BY STUDENTS IN THEIR FINAL COURSE PAPERS AT \\ THE ADVERTISING COURSE FROM THE FRANCISCAN UNIVERSITY
}

\author{
Daniela Venturini Mundstock ${ }^{2}$ e Taís Steffenello Ghisleni ${ }^{3}$
}

\section{RESUMO}

O presente artigo tem por objetivo realizar uma análise das principais temáticas utilizadas nos trabalhos finais do curso de Publicidade e Propaganda da Universidade Franciscana, pelos alunos, desde a primeira turma de 2013/2 até a de 2019/1. Com o aumento do interesse dos alunos em relação à novas áreas de estudo, são definidas também novas linhas de pesquisas, uma vez que os estudantes buscam trazer novos tópicos e assuntos a serem estudados e debatidos. Para tanto, um levantamento exploratório e descritivo foi realizado para identificar as temáticas utilizadas durante as 12 turmas que passaram pela instituição. Por conseguinte, percebeu-se uma grande mudança nas principais temáticas analisadas na pesquisa anterior e no presente artigo. As novas tecnologias influenciaram nos interesses de pesquisas, que, por sua vez, adentraram principalmente nas mídias digitais.

Palavras-chave: Comunicação. Publicidade e Propaganda. Temáticas.

\section{ABSTRACT}

This article aims to perform an analysis of the main themes used in the Final Graduation Papers at the Advertising Course from the Franciscan University, from the classes of 2013/2 to 2019/1. With the increasing interest of students about new areas of study, new lines of research are also defined, as students try to bring new topics and subjects to be studied and discussed. To this end, an exploratory and descriptive survey was conducted to identify the themes used by the 12 classes that studied at the institution. As a result, it was noticed there was a big change in the main themes analyzed in the previous research and in the themes analyzed in this article. New technologies influenced the research interests, which, in turn, focused mainly on digital media.

Keywords: Communication. Advertising and marketing. Theme.

\footnotetext{
${ }^{1}$ Iniciação Científica.

${ }^{2}$ Aluna do Curso de Publicidade e Propaganda (UFN) E-mail: danimundstock@gmail.com

${ }^{3}$ Doutora em Comunicação. Professora no curso de Publicidade e Propaganda e no Mestrado em Ensino de Humanidades e Linguagens (UFN). E-mail: taisghisleni@yahoo.com.br
} 


\section{INTRODUÇÃO}

O interesse na realização deste trabalho surgiu a partir da percepção sobre o crescente interesse dos alunos na busca por novas temáticas de estudo, sentindo assim uma necessidade de identificação de novas linhas de pesquisa para o curso. Assim, foi então realizada no curso de Publicidade e Propaganda da Universidade Franciscana uma pesquisa desenvolvida pelos acadêmicos Matheus Roberto de Oliveira e Elisiane Rosa Carneiro, sob orientação da Professora Taís Steffenello Ghisleni. No trabalho, realizado em 2013 e intitulado "Áreas de interesse: identificando as temáticas das monografias dos egressos do curso de publicidade e propaganda", foram analisadas as turmas de 2010/1 a 2013/1 e, a partir dele, o presente artigo busca dar continuidade à pesquisa, porém, analisando as turmas de 2013/2 até 2019/1.

Com o aumento do interesse dos alunos em relação à novas áreas de estudo, são definidas também novas linhas de pesquisas, uma vez que os estudantes buscam ir cada vez mais além do que já fora pesquisado antes, trazendo novos tópicos e assuntos a serem estudados e debatidos. Para Jacks (2008), as tendências de pesquisa da época eram definidas como "globalização, novas tecnologias, e-commerce, empresas ponto.com, nova economia, virtualidade". Hoje não são esses os temas mais estudados pelos alunos, pois há novas linhas de pensamento que agora foram inseridas e causaram interesse em uma escala muito maior.

No cenário atual, em que a internet é um dos principais meios para se fazer publicidade, é perceptível uma transformação rápida e efêmera dos assuntos. Por ser uma rede que disponibiliza conteúdos diversos e de fácil acesso, os assuntos acabam por tornar-se momentâneos, passageiros. O que era interessante agora, pode ser um conteúdo irrelevante amanhã. Por isso, é preciso estar sempre atento quanto as novas tendências. A mídia já passou por grandes evoluções e diferentes momentos até chegar ao cenário atual.

E não é somente a publicidade e as mídias que estão em constante mudança: o consumidor também. É necessário que as marcas estejam sempre informadas quanto às mudanças dos seus compradores, para que se possa entender por que transformações o seu público está passando. Ghisleni (2016, p.52) afirma que “com o passar do tempo os hábitos e comportamentos dos indivíduos são modificados, e com a publicidade ocorre o mesmo". Por isso, é preciso buscar também novas maneiras de atrair o público partindo do entendimento sobre o que cada espectador deseja.

A partir do contexto exposto, o presente artigo tem como objetivo analisar as temáticas usadas nos trabalhos finais de graduação pelos alunos do curso de Publicidade e Propaganda da Universidade Franciscana, nas 12 turmas formadas durante o período de 2013/2 a 2019/1. Em união à pesquisa anterior e na pesquisa atual será possível analisar se houve ou não mudanças notáveis das temáticas estudadas no curso de Publicidade e Propaganda da Universidade Franciscana. 
Bastos (2003, p. 17) afirma que monografia é "um trabalho acadêmico que tem por objetivo a reflexão sobre um tema ou problema específico e que resulta de um processo de investigação sistemática". Assim, é comum que a escolha do tema da monografia seja de uma área de interesse do autor, uma vez que o desenvolvimento do projeto, a análise e a reflexão, precisam ser significativos e o autor deve ter envolvimento com o assunto. Com essa aproximação, o pesquisador não se distanciará da sua temática de pesquisa e dos seus valores pessoais, deixando transparecer seu posicionamento referente ao assunto.

Segundo Salvador (1982, p. 45), é necessário superar a tendência de escolher grandes temas que, pela sua extensão, não possibilitam uma maior profundidade no assunto. É preciso também ter cuidado na hora de escolher a temática, uma vez que é necessário que se tenha material suficiente para poder pesquisar sobre o assunto, sem que haja fuga de tema. Assim, o autor poderá agregar referenciais teóricos, a fim de dar maior credibilidade ao seu trabalho.

Já as palavras-chave são o principal instrumento de buscas de um texto, pois elas refinam as buscas, facilitam os resultados relacionados à mesma temática e trazem precisão no assunto que está sendo pesquisado. Segundo definições da NBR 6028 da Associação Brasileira de Normas Técnicas (ABNT, 2003), palavra-chave é a palavra representativa do conteúdo do documento, escolhida, preferentemente, em vocabulário controlado. É indicado que sejam definidas o máximo de palavras-chave possível, para que assim as buscas relacionadas ao mesmo assunto sejam mais refinadas. Este procedimento, no âmbito dos artigos científicos, pode-se revelar útil para a indexação em mecanismos de pesquisa ou categorização do texto (ERCAN; CICEKLI, 2007).

\section{PUBLICIDADE E PROPAGANDA}

A partir do conceito definido pelas "Normas-padrão da atividade publicitária", elaboradas a partir da lei n. 4.680/65 e dos decretos n. 57.690/66 e n. 2.262/97, no item 1.1. do capítulo 1 (conceitos básicos), a "Publicidade ou propaganda: é nos termos do art. $2^{\circ}$ do dec. n. 57.690/66 qualquer forma remunerada de difusão de ideias, mercadorias, produtos ou serviços por parte de um anunciante identificado" (CENP, 1998). Dessa forma, para conseguir atrair a atenção do público de forma criativa, a publicidade e a propaganda precisam utilizar novas formas de vender um serviço ou produto.

Segundo Gonçalez (2009), é possível afirmar que a publicidade é definida a partir de três elementos principais: o anunciante, os veículos de comunicação e o profissional de publicidade. Os anunciantes, também chamados de clientes, são os que divulgam o produto ou serviço; os veículos são o canal por onde a publicidade é distribuída, como jornais, televisão, revistas, rádio, internet e etc. O profissional da publicidade é aquele que tornará a comunicação da empresa mais atrativa e interessante aos olhos 
dos consumidores, e que também define quais os melhores veículos a serem selecionados para que a mensagem atinja seu público-alvo.

Na Universidade Franciscana, o curso de Publicidade e Propaganda tem duração de oito semestres, ou seja, quatro anos, e suas disciplinas são ofertadas durante o turno da manhã, permitindo assim que os alunos realizem outras atividades durante a tarde. O próprio curso oferece os serviços de laboratórios voltados às áreas de comunicação, como Laboratório de Fotografia, Laboratório de Rádio, Laboratório Audiovisual, Agência Experimental, etc. Essas oportunidades ofertadas aos acadêmicos do curso fazem com que, ao mesmo tempo que os alunos tenham a chance de se aproximar mais da instituição, também tenham noção do que poderão enfrentar no mercado de trabalho.

\section{A EVOLUÇÃO DA COMUNICAÇÃo}

De acordo com uma pesquisa realizada pelo Conselho Executivo de Normas-Padrão - CENP e divulgada no site Meio Mensagem, em abril de 2019, a TV aberta continua sendo a mídia com o maior investimento e maior poder de atração das verbas dos anunciantes, com um total de 58,3\% dos investimentos. Os dados de 2018 foram praticamente iguais aos de 2017, ou seja, não houve uma evolução perceptível em relação à internet, que se encontra em segundo lugar, com 17,7\%, ainda com uma grande diferença ainda em relação à televisão.

Com o passar dos anos, o surgimento de novas tecnologias influenciou diretamente na forma de fazer publicidade. Agora jornais, rádio, televisão, agências de publicidade, outdoors e várias outras opções eram um bom meio para vender algum produto ou serviço. Com tantos meios de comunicação, foi preciso readaptar a publicidade para que fosse inserida nas novas tecnologias e que continuasse a atrair olhares de consumidores. E a tecnologia não parou por aí: a era dos smartphones tornou-se real.

Segundo publicado no Estadão de abril de 2019, conforme a 30 a Pesquisa Anual de Administração e Uso de Tecnologia da Informação nas Empresas, realizada pela Fundação Getúlio Vargas de São Paulo (FGV-SP), o Brasil tem hoje dois dispositivos digitais por habitante, incluindo smartphones, computadores, notebooks e tablets. Entre os aparelhos, o uso de smartphone se destaca: segundo o levantamento, há hoje 230 milhões de celulares ativos no País. Houve um aumento de 10 milhões no número de smartphones ativos em relação a 2018.

Ainda para Ghisleni (2016, p. 68), “o panorama da publicidade mudou muito nos últimos anos, e no setor online é que estas mudanças são mais visíveis, já que a publicidade precisou se adaptar aos novos tempos, em que a mobilidade e a comunicação integrada estão em foco". Com os celulares inteligentes de hoje em dia, a compra por um clique tornou-se tão fácil quanto ir ao mercado. Por causa das novas tecnologias, as empresas precisaram buscar novas formas de comunicação, para que pudessem adentrar nas redes sociais com uma linguagem mais humanizada, mostrando que se importam com seus consumidores. 


\section{METODOLOGIA}

A metodologia utilizada para a construção desta pesquisa é exploratória e descritiva. Foi feito um levantamento das temáticas utilizadas nos trabalhos finais de graduação das turmas de 2013/2 a 2019/1 do curso de Publicidade e Propaganda da Universidade Franciscana. Os dados que relatavam as temáticas utilizadas pelas 7 primeiras turmas foram coletados de uma pesquisa já realizada por Oliveira, Carneiro e Ghisleni (2013), e a esses dados somamos a coleta das próximas 12 turmas do curso.

Reforçamos que a coleta de dados foi contemplada de forma quantitativa e apreciou as temáticas já utilizadas nos Trabalhos Finais de Graduação das 19 turmas que concluíram o curso no período de 2010/1 a 2019/1. De posse dos dados a respeito de todas as temáticas utilizadas foi realizado um cruzamento de dados a fim de comparar o que mudou durante esse período.

\section{RESULTADOS E DISCUSSÕES}

Os resultados obtidos no trabalho de Oliveira, Carneiro e Ghisleni (2013), em uma análise realizada por meio do resumo e das palavras-chave, foi possível enquadrar as temáticas centrais dos trabalhos finais de graduação no curso de Publicidade e Propaganda em categorias distintas. Para melhor entendimento, foi desenvolvida uma tabela demonstrativa demonstrando quais são as temáticas e o número de vezes que cada uma aparece. Na tabela 1, foi distribuído os 146 trabalhos de conclusão de curso produzidos durante os anos de 2010 a 2013/1 e analisados, então, por Oliveira, Carneiro e Ghisleni (2013).

Quadro 1 - Temáticas centrais/categorias dos Trabalhos Finais de Graduação do Curso de Publicidade e Propaganda da Universidade Franciscana, dos acadêmicos do ano de 2010/1 até 2013/1.

\begin{tabular}{|l|c|}
\hline \multicolumn{1}{|c|}{ Temáticas } & Quantidade de trabalhos \\
\hline Marketing & 22 \\
\hline Consumo/Comportamento do Consumidor & 19 \\
\hline Discurso/representação/identidade & 15 \\
\hline Marca & 14 \\
\hline Publicidade e Propaganda & 14 \\
\hline Audiovisual & 10 \\
\hline Comunicação & 7 \\
\hline Internet/Mídias Sociais & 6 \\
\hline Cinema & 5 \\
\hline Moda & 4 \\
\hline Música & 3 \\
\hline Linguagem/significado & 3 \\
\hline Cultura & 3 \\
\hline Literatura e Comunicação & 2 \\
\hline Ética e Publicidade & 2 \\
\hline Estética & 2 \\
\hline
\end{tabular}




\begin{tabular}{|l|c|}
\hline Televisão & 1 \\
\hline Rádio & 1 \\
\hline Esportes & 1 \\
\hline Fotografia & 1 \\
\hline Política & 1 \\
\hline Perfil psicológico/psicologia & 1 \\
\hline Games/Jogos & 1 \\
\hline Eventos & 1 \\
\hline ONGs & 1 \\
\hline
\end{tabular}

Fonte: Oliveira, Carneiro e Ghisleni (2013).

Em relação aos resultados analisados no presente artigo, foram então verificados 193 (cento e noventa e três) trabalhos finais de graduação. A partir do mesmo meio de análise do trabalho anterior (resumo e palavras-chave), pode-se perceber 24 temáticas de estudo diferentes. Na tabela 2, foi distribuído os 193 trabalhos de conclusão de curso produzidos durante os anos de 2013/2 a 2019/1.

Quadro 2 - Temáticas centrais/categorias dos Trabalhos Finais de Graduação do Curso de Publicidade e Propaganda da Universidade Franciscana, dos acadêmicos do ano de 2013/2 até 2019/1.

\begin{tabular}{|l|c|}
\hline \multicolumn{1}{|c|}{ Temáticas } & Quantidade de trabalhos \\
\hline Mídias Sociais & 40 \\
\hline Estratégias & 23 \\
\hline Marca & 23 \\
\hline Audiovisual & 20 \\
\hline Gênero & 12 \\
\hline Cultura/identidade & 11 \\
\hline Cinema & 10 \\
\hline Comportamento do Consumidor & 10 \\
\hline Direção de arte & 6 \\
\hline Estética & 6 \\
\hline Marketing Esportivo & 5 \\
\hline Moda & 5 \\
\hline Marketing & 4 \\
\hline Foto & 3 \\
\hline Semiótica & 2 \\
\hline Product Placement & 2 \\
\hline Empreendedorismo & 2 \\
\hline Jingle & 1 \\
\hline Religião & 1 \\
\hline Design Thinking & 2 \\
\hline Neuromarteking & 1 \\
\hline Marketing Social & 1 \\
\hline Jogos & 2 \\
\hline Meme & 1 \\
\hline & 2 \\
\hline & 2 \\
\hline
\end{tabular}

Fonte: elaboração das autoras. 


\section{CONSIDERAÇÕES FINAIS}

Em relação ao primeiro estudo, realizado por Oliveira, Carneiro e Ghisleni (2003), pode-se perceber que a temática mais estudada é Marketing, ocupando 15\% do total das pesquisas, ou seja, 22 dos trabalhos. Em segundo lugar está "Consumo/Comportamento do Consumidor”, com 19 aparições (13\%); "Discurso/Representação/Identidade", tema que surgiu 15 vezes (10,2\%); "Marca" e "Publicidade e Propaganda", aparecendo em 14 oportunidades cada uma (9,6\%); e "Audiovisual", que foi escolhido 10 vezes como temática $(6,8 \%)$.

Já no presente estudo, a temática mais estudada é a de "Mídias Sociais", com um total de 40 dos 193 trabalhos estudados, o que resulta em 20,73\% do total. Essa é a grande diferença entre os trabalhos estudados: a partir de 2013, as redes sociais adentraram cada vez mais no espaço social e passaram a fazer cada vez mais parte do dia a dia das pessoas. Isso é comprovado nesse estudo, o qual percebe-se um aumento significativo de estudos relacionados à essa temática, uma vez que "Mídias Sociais", no período dos trabalhos analisados em 2010 à 2013/1, aparece somente em 6 monografias. O crescimento do interesse por essa temática se dá justamente pela grande utilização das mídias sociais nos dias de hoje, uma vez que grande parte da população e das empresas encontram-se inseridas na internet atualmente. Em Segundo e terceiro lugar temos "Estratégias" e "Marca", ambas com 23 trabalhos, resultando $11,92 \%$ cada uma.

A partir do objeto escolhido a ser estudado, os futuros publicitários buscam pesquisar áreas de maior conhecimento sobre a realidade na qual se inserem. Com a popularização das redes sociais, as quais os jovens estão parcialmente inseridos, as mídias tornaram-se temáticas interessantes para serem estudadas, a fim de compreender como as empresas devem e estão se portando na internet. Os acadêmicos querem estudar conteúdos envolventes, que façam a diferença e que somem em futuras pesquisas relacionadas às temáticas escolhidas por eles, buscando ir além do que já se foi estudado e trazendo inovação nas áreas de pesquisas.

\section{REFERÊNCIAS}

ABNT NBR 6028, Informação e documentação - Resumo - Apresentação. Disponível em: https:// bit.ly/2I9PWVr. Acesso em: 03 set. 2019

BASTOS, Lília da Rocha (Org.). Manual para a elaboração de projetos e relatórios de pesquisas, teses, dissertações e monografias. 6. ed. Rio de Janeiro: LTC, 2003.

CENP - Conselho Executivo das Normas-Padrão. Do relacionamento comercial entre anunciantes, agências de publicidade e veículos de comunicação, frente à lei nº 4.680/65. 1998. 
CENP - Conselho Executivo das Normas-Padrão. Do relacionamento comercial entre anunciantes, agências de publicidade e veículos de comunicação, frente à lei nº 4.680/65. 1998.

ERCAN, G.; CICEKLI, I. Using lexical chains for keyword extraction. Information processing and management, v. 43, p. 1705-1714, 2007. Disponível em: http://dx.doi.org/10.1016/ j.ipm.2007.01.015. Acesso em: 03 set. 2019

ESTADÃO CONTEÚDO. Brasil tem 230 milhões de smartphones em uso. Época Negócios, 2019. Disponível em: https://glo.bo/2U8HQP9. Acesso em: 03 set. 2019.

GHISLENI, Taís Steffenello. Portais institucionais na web: análise de anúncios publicitários no ecossistema midiático. 25/11/2016. 297p. Tese (Doutorado). Universidade Federal de Santa Maria. Santa Maria, Centro de Ciências Sociais e Humanas, Programa de Pós-Graduação em Comunicação. 2016.

GONÇALEZ, Márcio Carbaca. Publicidade e Propaganda. Curitiba: IESDE Brasil S.A., 2009.

JACKS, Nilda (Coord). Meios e audiências: a emergência dos estudos de recepção no Brasil. Porto Alegre: Sulina, 2008.

OLIVEIRA, Matheus Roberto de; CARNEIRO, Elisiane Rosa; GHISLENI, Taís Steffenello. Áreas de interesse: identificando as temáticas das monografias dos egressos do curso de Publicidade e Propaganda. Disciplinarum Scientia. Série: Artes, Letras e Comunicação, S. Maria, v. 13, n. 1, p. 97-105, 2012.

SALVADOR, Ângelo Domingos. Métodos e técnicas de pesquisa bibliográfica, elaboração e relatório de estudos científicos. 10. ed. Porto Alegre: Sulina, 1982, n. 235, p. 45.

SANTAELLA, Lucia. Linguagens líquidas na era da mobilidade. São Paulo: Paulus, 2007.

SANTAELLA, Lucia. Redação publicitária digital. Curitiba: InterSaberes, 2017. 